LATOUR, Bruno; LÉPINAY, Vincent Antonin. La economía, ciencia de los intereses apasionados: introducción a la antropología económica de Gabriel Tarde. Buenos Aires: Manantial, 2009. $128 \mathrm{p}$.

\title{
Andressa Lewandowski
}

Universidade de Brasília* - Brasil

\section{Quando as paixões podem mover as ciências: a economia de Gabriel Tarde}

Se o antropólogo Bruno Latour deve alguma coisa ao renegado pensador francês Gabriel Tarde (1843-1904), a meu ver certamente é a paixão. A paixão de Latour em transformar a ciência em alguma coisa menos compartimentalizada onde sujeitos e objetos, natureza e cultura, humanos e não humanos deixam de ocupar lugares hierarquicamente diferentes se contraponto à lógica durkeimiana que funda as ciências sociais como uma busca de lógicas classificatórias.

Mesmo que explicitamente não tenha havido uma "batalha inaugural" das ciências sociais entre Durkheim e Tarde, a sociologia científica de Durkheim vencia com busca de leis universais a microssociologia tardiana onde os fenômenos sociais são reduzidos a processos mentais que envolvem interações. Segundo Tarde, o que funda a vida social seria um tipo de contaminação que vai sempre de indivíduo a indivíduo sem deter-se a eles. Sociedade seria então "uma coleção de seres com tendência a se imitarem entre si":

Mas isso quer dizer que cada coisa é uma sociedade e que todas as coisas são sociedades. E é bastante notório que a ciência tenda, mediante uma sequência lógica dos seus movimentos anteriores, a generalizar estranhamente a noção de sociedade. Ela fala-nos de sociedades celulares, por que não de sociedades atômicas? Isso para não falar das sociedades de estrelas, dos sistemas solares. Todas as ciências parecem destinadas a tornarem-se ramos da sociologia. (Tarde, 1999, p. 58, tradução minha).

\footnotetext{
* Doutoranda em Antropologia Social.
} 
Em recente retomada realizada por diversos autores da obra de Tarde, aos quais Latour se soma, as ciências sociais são provocadas a repensar seus repertórios analíticos e metodológicos. A última publicação de Bruno Latour em conjunto com Vincent Antonin Lépinay, La economía, ciencia de los intereses apasionados. Introducción a la antropología económica de Gabriel Tarde, aparece, então, quase como uma homenagem ao mestre, apresentando as bases das construções teóricas de Gabriel Tarde, sobretudo aquelas menos conhecidas apresentadas nos dois volumes de Psychologie économique (1902). O texto curto, que muito se assemelha a uma resenha, é divido em três capítulos e remonta parte da teoria de Gabriel Tarde como uma forma de ajudar o leitor a seguir os caminhos traçados pelo autor para pensar a economia.

Já na primeira frase do texto somos convidados a fazer uma inversão, talvez um pouco incômoda às ciências da economia ou mesmo à nossa própria percepção de economia: "Nada em economia é objetivo." A economia da qual estamos acostumados a falar, que diz respeito a valores monetários, juros, mercado, interesses ou mesmo dádivas e reciprocidades, se depara com questões como crença e desejo. Crenças e desejo, no argumento de Tarde, são quantidades psicológicas que podem ser medidas e comparadas.

Segundo Tarde, o valor - questão central para pensar economia - é uma dimensão eminentemente psicológica que depende justamente de crenças e desejos, e pode ser quantificado porque possui certa intensidade. Quando fala em psicológico Tarde não está se referindo a uma dimensão interna aos sujeitos (o que seria para ele a dimensão intrapsicológica), mas sim àquilo que há de mais social em nós. Noções como psicológico, subjetivo, social seriam então equivalentes. Sendo assim a oposição sociedade/individuo não faz sentido nas ideias de Tarde. Como também não faz sentido na teoria de Latour, justamente porque sociedade e individuo seriam agregados provisórios, "estabilizações parciais", como "nós na rede". Seguindo Tarde tudo é sociedade.

A noção de sociedade e social assim sofre sua primeira transformação. Segundo Latour (2006, p. 16), um dado fenômeno era dito social ou revelador da sociedade:

[...] a partir do momento em que podia ser definido atribuindo-lhe propriedades específicas, algumas negativas - não devia ser "puramente" biológico, linguístico, econômico, ou natural - e outras positivas - deveria produzir, reforçar, exprimir, manter, reproduzir ou subverter a ordem social. Ficando este domínio definido, mesmo que em termos muito vagos, poder-se-ia então utilizá-lo para

Horizontes Antropológicos, Porto Alegre, ano 17, n. 35, p. 393-399, jan./jun. 2011 
dar conta de outros fenômenos sociais - o social poderia explicar o social - bem como para fornecer um certo tipo de explicação daquilo que outras disciplinas não conseguem dar conta - um apelo aos "fatores sociais" poderia explicar as "dimensões sociais" de fenômenos não sociais.

Com Tarde o social passa a abarcar todas as dimensões, resistindo às oposições individuo e sociedade como também parte e todo, humanos e não humanos, objeto e sujeito. A economia deixa então de ser uma dimensão separada, podendo ser pensada a partir de outros elementos e aproximada a noções antes tomadas como sendo de outros, campos como a psicologia. "A tendência de matematizar a ciência econômica e a tendência a psicologizá-la, longe de serem tendências irreconciliáveis devem sim prestar apoio mútuo." (p. 96, tradução minha).

Mesmo adentrando nas dimensões subjetivas da noção de valor, o central na posição de Tarde nessa leitura feita por Latour e Lépinay é que valor pode e deve sempre ser quantificado. As três categorias de valor apresentadas: "valor verdade", "valor utilidade" e "valor beleza", são descritas como se existisse uma escala. A crítica à economia política não estaria então em quantificar demais, pelo contrário, segundo Tarde, os economistas quantificam menos do que deveriam, pois estariam concentrados apenas no signo monetário ou ainda em estender as quantificações de riquezas como metáforas para analisar as demais dimensões de valor. Latour e Lépinay chamam de "valorímetro" todos os dispositivos que permitem fazer visíveis e legítimos os juízos de valor capazes da captar a "alma humana", que formam a base do que Tarde denominaria de economia.

Para medir as diversas dimensões de valor Tarde faz uma distinção entre dois tipos de medida: aquela capaz de captar o estado real, que o autor chama de medida-medida e aquela capaz de medir o mundo social, a medida mensurante. Seguindo essa distinção é possível pensar que existem muitos outros instrumentos capazes de quantificar a economia. Como se mede a honra de um homem, perguntaria Tarde, e sua reposta está colocada nas chamadas quantidades sociais. Os vínculos entre as coisas ou os domínios não estão relacionados à influência de uns sobre outros, carregam vínculos muito mais íntimos que não são de natureza. Para quantificar é necessário buscar os tipos disponíveis do que Latour e Lépinay chamam de quantum.

Economia seria então, como explicita o nome do livro, uma ciência dos interesses apaixonados, porém não são interesses individuais. Assim não são 
apenas os atos dos sujeitos que têm importância, mas toda uma rede de interações. Segundo Tarde o erro maior da economia é apenas levar em conta uma preocupação com motivações exteriores.

Latour e Lépinay apontam que todas as interações e entrecruzamentos tecem o mundo, e o transformam através de três etapas: repetição de uma primeira diferença, oposição criada pela repetição (oposição seria uma contra repetição, uma repetição inversa) e adaptação, que permite sair provisoriamente dessas oposições através de novas diferenciações. $\mathrm{O}$ fundamento do mundo seria a imitação, uma mistura de repetição e invenção, duas forças que mobilizam crenças e desejos.

O que está no centro da teoria de Tarde é a noção de inovação e uma sequência de invenções. As inovações são previamente repetidas e terminam por combinar-se, ajustar-se se transformando. Nas palavras de Tarde:

En suma, el problema se resume a esto: aprehender lo más estrechamente posible la génesis de las invenciones y las leyes de sus imitaciones. El progreso económico supone dos cosas: por una parte, una cantidad creciente de deseos diferentes, pues, sin diferencia en los deseos, desaparece todo intercambio posible $\mathrm{y}$, con cada nuevo deseo diferente que aparece, la vida del intercambio se aviva. Por otra parte: una creciente cantidad de ejemplares semejantes, de cada deseo considerado aparte; pues, sin esa semejanza, desaparece toda industria posible y, cuando más se extienda esa semejanza o se prolongue, más se ampliará o se consolidará la producción. (p. 57).

A noção de diferença ${ }^{1}$ é fundamental para pensar a obra de Tarde. É a partir das diferenças constitutivas que o autor pensa nas similaridades por meio do contágio pensado como comunicação de crenças e desejos. Através da crença o eu se distingue e pelo desejo ele se modifica. É por meio da diferença que as coisas começam e terminam. Quando exclama que "existir é ser diferente", Tarde (1999) coloca no centro de suas atenções a noção de invenção que, uma vez repetida, suscita enumeráveis lutas que só podem ser resolvidas a partir de novas invenções.

As diferenças são produzidas pelas invenções e sua repetição permite sua difusão, mesmo assim os conflitos são inevitáveis, e segundo Tarde nenhum

1 Diferença e repetição são pontos-chave da argumentação tardiana, retomada no livro homônimo de Gilles Deleuze (1968). 
harmonia preestabelecida permite sua solução; seria necessário então inventar outras soluções para engendrar provisoriamente outras inovações que, ao repetir-se, produzirão outras diferenças, e o ciclo recomeça (p. 91). Invenções dependem da crença, pois relacionam entidades até então separadas, que precisam de confiança para aceitar as primeiras transformações.

$\mathrm{Na}$ leitura de Latour e Lépinay, as ciências propostas por Tarde fazem mais do que conhecer o mundo, elas se agregam a ele, o complicam e simplificam. Não se pode imaginar ciência então que se coloque acima da moral, que "reine friamente sobre os indivíduos racionais", que passe por cima dos interesses apaixonados.

O universo de Gabriel Tarde é composto por três esferas: a vital, a físicoquímica e a social. A diferença entre essas esferas não diz respeito à sua natureza, mas apresentam uma diferença de grau. Aqui vale a pena retomarmos a noção de mônadas, emprestada de Leibniz e atualizada por Tarde. O mundo deixa de ser composto por elementos homogêneos e, ao contrário, passa por forças heterogêneas idênticas chamadas por Tarde de mônadas. Mesmo como forças idênticas, as mônadas nunca permanecem nesse estado, pois agem conflitivamente provocando transformações por meio de ações criativas que as diferenciam e propagam sempre de modo relacional. Existiria assim em cada elemento o desejo de se associar a outro. Crenças e desejo são, no argumento de Tarde, as quantidades que provocam as mobilizações, as relações. Segundo Lazzarato (2006, p. 32),

[...] a recuperação que esse autor faz da idéia "leibniziana" de "mônada" como designadora do que constitui o mundo. Sua preocupação é o abismo que se instaura entre sujeito e objeto, natureza e sociedade, sensível e inteligível, alma e corpo após o advento da filosofia de René Descartes. Sua intenção é "restituir a cada mônada sua própria potência de invenção e resistência". Não tanto para negar as oposições existentes (sujeito/objeto, natureza/cultura, capital/trabalho etc.), mas para liberar suas potências e virtualidades. Dois importantes aspectos quanto às mônadas "tardianas" dizem respeito ao fato de elas constituírem diferenças - existir, portanto, é diferir - e ao fato de sua ação referir-se ao sentir: agir é modificar o modo de sentir junto. Compreende-se assim que o acontecimento - ou seja, a criação e efetuação de mundos -, sob o prisma da monadologia tardiana, significa uma ação sobre os afetos (crenças, desejos, vontades, inteligências etc.). Se virmos a ação como criação e efetuação de mundos, a distinção hierárquica entre fazer e dizer, entre produção material e ideologia, entre sujeito e objeto, entre a coisa e o signo, não funciona mais. 
O que Tarde faz com a atividade econômica é colocá-la em meio a esse fluxo universal das mônadas, entendendo as invenções da economia como a amplificação das invenções da natureza.

Distinguir la tierra, el capital y el trabajo no es muy revelador. Si se va hasta el fondo de esas cosas, se encuentra que ellas se resuelven en sí mismas en repeticiones de diversas naturalezas. ¿Qué es la tierra si no el conjunto de fuerzas físico-químicas y vivientes que actúan unas sobre las otras, una por las otras, y que consisten, unas, calor, luz, electricidad, en combinaciones y sustancias químicas, en repeticiones irradiantes de vibraciones etéreas o moleculares; las otras, plantas cultivadas y animales domésticos, en repeticiones no menos irradiantes y expansivas de generaciones conformes al mismo tipo orgánico o una nueva raza creada por el arte de los jardineros y los criadores? (p. 73, grifo do autor).

As verdadeiras fontes do valor seriam as variações sutis de crenças e desejos, e não, como argumentaria Karl Marx, trabalho e produção. Tarde diferencia o capital por duas questões. A primeira delas: o "capital essencial", como conjuntos de invenções reinantes, fontes primárias de toda a riqueza, e a segunda, o capital auxiliar menos útil, é a parte dos produtos nascidos dessas invenções primeiras que serve para criar outros produtos. $\mathrm{O}$ trabalho, seguindo o argumento, nunca pode divergir ou operar diferenças nas oposições por si só, ele pode unicamente repetir. A distinção entre capital e trabalho nos remete a uma distinção entre um modelo e uma cópia. O trabalho aqui é tomado como força bruta, que não pode modificar sua trajetória de maneira autônoma.

Todas as ideias apresentadas até aqui levam Gabriel Tarde a não acreditar em rupturas nos sistemas econômicos. O que acontece, segundo o autor, é uma extensão, uma intensificação das redes de imitação, uma prolongação das redes. A trajetória econômica de Tarde, segundo Latour e Lépinay, não é conduzida por estruturas subjacentes ou leis exteriores. A ruptura de Tarde está no argumento de que a economia não está inserida no social justamente porque o social não é um domínio próprio, senão um princípio de associação e contaminação, assim como também não existe um reino no político que chegue a delimitar fronteiras. O que existe são tecidos intercruzados de desejos e crenças "em via de expansão". Em vez de falar em produção de riquezas Tarde apresenta a noção de repetição econômica; dessa forma, segundo o autor, 
[...] entenderemos las relaciones que los hombres mantienen entre sí desde el punto de vista de la propagación de sus necesidades semejantes, de sus trabajos semejantes, de sus juicios semejantes acerca de la mayor o menor utilidad de esos trabajos y de sus resultados, de sus transacciones semejantes. [...] Con la oposición económica, me propongo a comprender las relaciones de los hombres desde punto de vista de la contradicción psicológica y desapercibida de sus necesidades y de sus juicios de utilidad, del conflicto más aparente de sus trabajos mediante la competencia, las huelgas, las guerras comerciales. [...] Con la denominación adaptación económica se tratarán las relaciones que los hombres mantienen entre si desde el punto de vista de la cooperación de sus antiguas invenciones para la satisfacción de una necesidad nueva o para la mejor satisfacción de una necesidad antigua [...]. (p. 97, grifo do autor).

O econômico de Tarde, ao tecer suas redes, também contém as questões políticas. O econômico e o político se referem ao mesmo objeto, percorrem as mesmas redes. A distinção entre eles está colocada nos tipos de organização que promovem: no caso dos políticos, colaboração, e para os econômicos, utilização recíproca. Há aqui, segundo Latour e Lépinay, uma "antropologia econômica das mais profundas" (p. 106), a qual somente se pode praticar com a condição de se ter restabelecido um vínculo entre avaliações do coração humano e os cálculos que permitem a riqueza das nações. A sociologia de Tarde nos tira a harmonia, as leis naturais, as ideias de totalidade e finalidade. O todo social de Tarde está por fazer, por meio de invenções. O todo social seria então um devir.

\section{Referências}

DELEUZE, G. Différence et répetition. Paris: PUF, 1968.

LATOUR, B. Como prosseguir a tarefa de delinear associações? Configurações, n. 2, p. 11-27, 2006.

LAZZARATO, M. As revoluções do capitalismo. Rio de Janeiro: Civilização Brasileira, 2006.

TARDE, G. Monadologie et sociologie. Paris: Les Empêcheurs de penser en rond: Institut Synthélabo, 1999. 
JASANOFF, Sheila (Ed.). States of knowledge: the co-production of science and social order. London: Routledge, 2004. 317 p.

\section{Rodrigo Ciconet Dornelles \\ Universidade Federal do Rio Grande do Sul* - Brasil}

A área dos Science and Technology Studies (STS) é relativamente recente, sobretudo na academia brasileira. Esse é um campo que, apesar de sua gradual expansão, sobretudo no contexto acadêmico norte-americano e britânico, ainda engatinha quando nos referimos à sua consolidação nos trópicos. Nesse quadro, States of knowledge, um livro de ensaios organizado pela pesquisadora norte-americana Sheila Jasanoff, ${ }^{1}$ merece amplo espaço de reflexão. De fato, States of knowledge é uma obra essencial não somente para aqueles que se interessam pela emergente área dos STS, procurando entender os vínculos existentes entre ciência e sociedade, ou mais especificamente entre conhecimento científico e suas dimensões sociopolíticas, mas também para os que buscam novas alternativas teóricas e conceituais nas ciências sociais como um todo.

No primeiro capítulo, intitulado "The Idiom of co-production", Jasanoff - mais do que introduzir o livro - apresenta o estado da arte do campo em questão, sublinhando como "ciência e tecnologia permeiam a cultura e a política da modernidade" (p. 1, tradução minha). Além disso, ela aponta para a tão relevante e presente questão da interdisciplinaridade, característica do campo dos STS, e que se faz presente na multiplicidade não só refletida nos objetos de estudo dos diversos autores que colaboraram com esse livro, mas também nas suas temáticas e nos seus enfoques metodológicos. Ademais, explícita

* Mestrando em Antropologia Social.

1 Sheila Jasanoff é Pforzheimer Professor em Science and Technology Studies na Harvard Kennedy School. Pioneira no campo dos STS, é autora de inúmeros artigos e livros, entre eles: Handbook of Science and Technology Studies (Jasanoff et al., 1995); Science at the bar: law, science and technology in America (Jasanoff, 1995); e o mais recente, Designs on nature: science and democracy in Europe and the United States (Jasanoff, 2005). 
ou implicitamente, todos os artigos que o compõem dão conta da dimensão política que permeia a ciência e a tecnologia.

States of knowledge não é um livro que procura "simplesmente" reunir diversos estudos de casos empíricos à luz de conceitos e teorias já consagrados nos STS. Procura, antes de tudo, fornecer um instrumental teórico e conceitual especialmente para os estudos que tenham a ciência e a tecnologia como objeto de reflexão. Assim, logo no primeiro capítulo, Jasanoff apresenta o conceito que, segundo ela, conecta os distintos textos e que, efetivamente, é utilizado pelos diversos autores do livro: a coprodução.

Elaborado no "idioma" da coprodução, a autora propõe analisar as relações entre ciência e sociedade por meio das interações entre pessoas, ideias, instituições e objetos materiais. Com isso, almeja colocar em questão "as categorias mais básicas do pensamento social - tais como estrutura e agency, natureza e cultura, ciência e política, estado e sociedade" (p. 2, tradução minha). Enfocando em particular a relação entre o conhecimento (nesse caso, o conhecimento científico) e o social (sempre em construção), o "idioma" da coprodução mostra como o conhecimento científico e tecnológico é constituído e constitutivo das práticas sociais, identidades, normas, convenções, discursos, instrumentos e instituições.

Podemos classificar os ensaios que compõem o corpo do livro em três grandes blocos: ${ }^{2}$ os que tratam de instituições e agências governamentais internacionais (os capítulos de Miller; Thompson; Waterton e Wynne; Storey); os que têm como objeto empírico as próprias comunidades de cientistas (Hilgartner; Rabeharisoa e Callon; Lynch; Carson), e, finalmente, os trabalhos que dão conta das relações explicitamente políticas, entre cientistas e o Estado (Dear; Dennis; Ezrahi).

Já no primeiro ensaio, ao tratar de mudança climática, Clark Miller examina a produção de uma ciência específica desse tema, não como algo aplicado a uma realidade preexistente, mas como algo que é parte constitutiva dessa mesma realidade. Paralelamente, o autor coloca em xeque uma visão simplista da ideia de globalização, já que entende que essa é constantemente

\footnotetext{
Cabe ressaltar que o modo de organização para descrever os distintos capítulos é, em alguma medida, arbitrário e contingente. Poderia, ao contrário do que foi feito, dividir os capítulos, por exemplo, em dois grandes grupos: os que tratam de objetos históricos e os que tratam de contemporâneos; ou os que tratam do objeto a partir de instituições e os que tomam a ciência a partir de agentes não institucionais.
}

Horizontes Antropológicos, Porto Alegre, ano 17, n. 35, p. 400-404, jan./jun. 2011 
reconstituída em uma ordem política global imaginada. Ainda tendo o "ambiente" como objeto de estudo, Charis Thompson utiliza o idioma da coprodução para analisar a transição do status do elefante africano, previamente visto como uma espécie entre tantas outras da fauna africana, para uma espécie regionalmente diferenciada que necessita de intensa proteção. Para tanto, examina a Convenção de Comércio Internacional de Espécies de Fauna e Flora (CITES, na sigla em inglês), além de considerar outros atores tais como turistas, mercadores de marfim e ativistas do movimento ambiental. No processo mostra como a construção de discursos sobre o "natural" transcende o particular, se conectando a um complexo jogo de instituições, identidades, conhecimentos e poder.

Claire Waterton e Brian Wynne enfocam a European Environment Agency (EEA), mostrando como a ciência dessa instituição é intimamente ligada a uma identidade europeia. Contribuem, de tal forma, para entendermos em que medida uma agência científica supranacional atua para ser produzida, por um lado, e produtora, por outro, de uma ordem política nascente. É um intento, portanto, não somente de tratar ciência e política bem como o natural e o social simetricamente, mas também de tratar uma instituição como um agente articulador na construção do conhecimento científico e de identidades. No último artigo do grupo, William Storey realiza uma análise histórica da fundação do Imperial Department of Agriculture for the West Indies. A partir desse caso, Storey vai além de uma descrição da influência mútua entre ciência e política. Ele descreve essas esferas como duas instâncias de um todo, ontologicamente ligadas. Dessa maneira, o autor desconstrói a ideia de desenvolvimento, mostrando, na ótica da coprodução, como ciência e tecnologia são objetos carregados de história e de relações de poder.

Se, no primeiro bloco de ensaios, observa-se a análise de instâncias altamente formalizadas e, sobretudo, institucionalizadas, num segundo grupo, encontramos atores sociais - especialmente cientistas - como principal ponto de partida. Nesse sentido, através do estudo de um grupo de geneticistas, Hilgartner tenta borrar distinções clássicas nas ciências sociais, tais como: micro e macro, ciência "pública" e ciência "privada", mostrando como, na produção de conhecimentos, a questão da propriedade e das patentes não é construída a posteriori, mas faz parte da ciência já no contexto do laboratório; quer dizer, ele toma esse espaço como produtor não só de fatos e máquinas, mas também de propriedade e donos. Em um caminho muito semelhante ao 
seguido por Hilgartner, centrado essa vez numa instituição não governamental - a Association Française contre les Myopathies -, Vololona Rabeharisoa e Michel Callon mostram como indivíduos leigos negociam aspectos da prática e da pesquisa nessa área com médicos e cientistas. Conforme os autores, é por meio dessa "organização reflexiva" que novas práticas discursivas e organizacionais reordenam a ciência médica no contexto contemporâneo. De certa forma, Michael Lynch, no capítulo seguinte, é outro que analisa, em um contexto legal norte-americano relativamente atual, a coprodução de conhecimentos leigos e especializados. $\mathrm{O}$ autor realiza seu objetivo enfocando os aspectos ditos sociais que estão inseridos no universo do expert (perito) dos tribunais. Evidenciando as relações entre o contexto micro e o macro, sugere como a reprodução de fronteiras entre ciência e não ciência se associa a determinado contexto das democracias liberais. Nestas, tanto as categorias de "cientista" e "especialista" quanto os termos utilizados são coproduzidos nas interações que ocorrem no tribunal.

Encerrando esse segundo bloco, aparece o ensaio de John Carson sobre a medição da capacidade intelectual, no qual lança mão, tal como Storey, de recursos históricos. Esse capítulo tem como tema a construção da ideia de inteligência em dois diferentes contextos geográficos - os Estados Unidos e a França -, em um mesmo período histórico - o princípio do século XX. Carson argumenta que: as diferenças entre os dois estilos nacionais de avaliar o mérito e, consequentemente, a definição de inteligência, nos dois países, deve-se especialmente a duas formas divergentes de entender a questão da equidade. Ou seja, segundo esse autor, as diferenças no que diz respeito ao entendimento do mérito e da inteligência que são constituídos nessas duas culturas políticas se remeteriam às relações entre ciência, política e sociedade.

Finalmente, os últimos três ensaios, que compõem o terceiro bloco, consideram os conflitos da ciência com outras formas de autoridade. Neles, segundo Jasanoff, a coprodução ajuda a entender como diferentes formas de autoridade são constituídas, incorporadas, colocadas à prova e reestabilizadas. Peter Dear, na sua análise dos filósofos naturais do século XVII, frisa como eles relacionavam a autoridade civil e epistemológica na Europa de então para legitimar um determinado tipo de conhecimento. Ao problematizar a ideia de expertise, tal como Lynch e Carson, volta à constatação de que a relação entre ciência e Estado não é algo dado. Michael Dennis, por sua vez, enfoca os 
conflitos nos Estados Unidos do pós-guerra sobre o financiamento da ciência, sublinhando o papel do Estado na construção da ordem sociotécnica.

Yaron Ezrahi, no último capítulo da coletânea, aborda o que chama de implicações recentes do declínio do que seria a síntese iluminista entre o conhecimento e a política e do surgimento de uma nova configuração do fazer e do conhecer político. Descreve, em particular, os mediadores-chave na transformação de sabedoria em conhecimento, de conhecimento em informação. Finalmente, sublinhando o papel da mídia no cenário contemporâneo, fala do surgimento de um novo fenômeno: a "exformação", a produção de informações em que a inteligibilidade por uma grande plateia prima sobre antigos valores como a fidedignidade ou precisão. É, portanto, um exemplo final de aplicação do idioma da coprodução no contexto das democracias contemporâneas, na análise de processos que são simultaneamente políticos, sociais e científicos.

Para complementar, no posfácio, também escrito pela organizadora, são retomadas, de forma mais concisa, as principais contribuições trazidas pelos inúmeros artigos, além de colocar em relevo, mais uma vez, as relações existentes entre ciência, tecnologia, política e sociedade, analisadas à luz do idioma da coprodução.

\section{Referências}

JASANOFF, S. Science at the bar: law, science and technology in America. Cambridge: Harvard University Press, 1995.

JASANOFF, S. Designs on nature: science and democracy in Europe and the United States. Princeton: Princeton University Press, 2005.

JASANOFF, S. et al. Handbook of Science and Technology Studies. Thousand Oaks: Sage Publications, 1995. 
ALGRANII, Joaquín M. Política y religión en los márgenes: nuevas formas de participación social de las mega-iglesias evangélicas en la Argentina. Buenos Aires: Ciccus, 2010. 360 p.

\section{Aldo Ameigeiras}

\section{Universidad Nacional de General Sarmiento - Argentina}

El libro escrito por Joaquín Algranti constituye un aporte en el conocimiento del pentecostalismo Latinoamericano, uno de los fenómenos religiosos más dinámicos de los últimos tiempos y sus peculiaridades en la Argentina. Resultado de la investigación realizada en el marco de su Tesis de Doctorado, el autor ha logrado, en el texto en cuestión, conciliar la rigurosidad académica con un estilo claro y ameno, tanto para los especialistas en la temática como para los interesados en la misma en general.

A lo largo de siete capítulos se transita por la complejidad de los nuevos escenarios y situaciones en que se despliega el pentecostalismo. Así desde las relaciones entre la religión y la política, pasando por las principales etapas del pentecostalismo en la Argentina y las singularidades de las mega iglesias y la identidad evangélica en el contexto de la vida cotidiana se pasa a abordar la singularidad de la mirada neopentecostal en el país para culminar con la complejidad del discurso evangélico sobre el liderazgo. Un recorrido pleno de información que incrementa la presencia de interrogantes y la búsqueda de nuevas respuestas.

Al avanzar en la lectura se tiene la impresión de estar frente a una investigación que reivindica la relevancia de hacer trabajo cualitativo en donde tanto el abordaje etnográfico como las entrevistas han servido claramente a la comprensión de la temática. Así se lleva a cabo un adecuado trabajo metodológico que se explicita adecuadamente en la construcción del texto como en la forma y el modo en que son abordados los testimonios. Se manifiesta así un planteo hermenéutico en el que la mirada de los actores conforma una instancia fundamental desde donde desplegar la complejidad del análisis. En los primeros capítulos juntamente con una reflexión acerca de la relación entre la religión y la política el autor avanza en considerar el surgimiento de lo que 
llama la irrupción del movimiento evangélico y en particular pentecostal en la sociedad Argentina. De esta manera luego de aludir a la diversidad de trabajos que se han realizado sobre el mismo pasa sin embargo a enfatizar la necesidad de continuar estudiando este fenómeno religioso que indudablemente aparece como uno de los más fecundos de los últimos años. Una instancia en donde es factible observar la potencialidad de articulación del neopentecostalismo especialmente con formas propias de la cultura de sectores medios de la sociedad, como también su apreciación de lo que denomina la "visión" en el mundo pentescostal y en la Iglesia Rey de Reyes (que analiza en particular). Reflexiones que inevitablemente nos conducen a preguntarnos acerca del carácter de dicha mirada y práctica pentecostal. En la apreciación acerca de los "nuevos escenarios y nuevos líderes" encara las "nuevas formas organizativas" considerándolas en forma inescindible del surgimiento de dichos líderes. Un fenómeno organizativo que aparece así directamente relacionado con la forma en que un grupo religioso resuelve su relación con la cultura y la sociedad y su vinculación con el poder político. Un tipo de perspectiva en la cual la flexibilidad y la adaptabilidad al medio aparecen como elementos claves a la vez que la organización celular que se explicita no solo no es contradictoria con los liderazgos, sino por el contrario constituye un elemento fundamental a tener en cuenta. El surgimiento de los nuevos liderazgos aparece entonces como un eslabón fundamental de una preocupación centrada en el adentro de la Iglesia y su paso a una preocupación marcada por la problemática del "afuera". Los liderazgos surgidos como mediación entre los núcleos duros de la organización y las células de la misma constituyen también un trampolín fundamental para la inserción en el mundo social y claramente para un nuevo redimensionamiento y revalorización de la vinculación con la política.

Una perspectiva que sin embargo se refiere no solo a características de la trama socio cultural sino también y fundamentalmente de ciertas modalidades del carácter organizativo y estructural del neopentecostalismo, en este caso en particular las mega-iglesias relacionado con su capacidad para llevar a cabo las adecuaciones estructurales y organizativas que le permitan adaptarse a un nuevo momento y necesidad histórica avanzando en desplegar lo que Joaquín Algranti denomina como una "estructura en movimiento". Las mega-iglesias como estructuras flexibles, cambiantes, dinámicas que le permiten redefinir sus prioridades institucionales en función de nuevos objetivos. Un modelo de organización eclesiástica que refuerza sus capacidades adaptativas. 
Asimismo resulta interesante su análisis acerca de la vida cotidiana y la identidad evangélica. Una instancia en donde aparecen las creencias, las prácticas rituales, las expresiones verbales de la fe y el cuerpo. Tres instancias a través de las cuales es posible observar un fenómeno vertebrador de la práctica pentecostal que pasa tanto por el despliegue de un tipo de adhesión "integradora" y "total" como profundamente recuperadora de la presencia vital. En donde se genera tanto una "integración" como una "resignificación" de prácticas y situaciones de la vida cotidiana. Una instancia en donde se establece una nueva relación del sujeto con la mirada, el cuerpo y el lenguaje y que resulta sintetizada a través de la acción articuladora de la experiencia. Allí cobra significación también la relevancia del lenguaje corporal que se manifiesta en gestos, prácticas y comportamientos que implican la puesta en escena de lo corporal desplegado en la dramaturgia litúrgica. Una situación que lo llevará también a sostener no solo que el mundo espiritual deviene en "soporte y potenciador de las prácticas" sino fundamentalmente una de sus principales hipótesis expresada en términos de considerar que "la espiritualización de la vida cotidiana que emprende el neo-pentecostalismo en este momento preciso de la historia, no aleja al hombre del mundo sino que lo acerca más, lo pone al alcance de la mano ofreciendo múltiples canales para intervenir sobre en distintas direcciones" (p. 179). Nos preguntamos entonces, ¿Estamos aquí ante una hipótesis de trabajo, un punto nodal capaz de explicar la dinámica pentecostal o sencillamente ante una afinada interpretación de la situación del anclaje del pentecostalismo en la realidad? En principio el autor nos plantea que se trata de un proceso de consolidación identitario que no se despliega disociadamente de la vida cotidiana. Y es allí donde aparecen algunas nociones fuertemente relevantes desde nuestra perspectiva e incluso más, quizás uno de los puntos centrales de la reflexión en cuanto avanza en plantear el sentido del "estar en el evangelio". Una apreciación que no podemos dejar de asociar con la profunda significación que dicho "estar" posee en los pliegues de la cultura popular. Un estar en el que avanza cuando se profundiza, recuperando el lenguaje de los informantes en cuanto se genera una revalorización de un "estar en el evangelio" como sinónimo de un "estar en movimiento". Un movimiento que, al articularse con las apreciaciones acerca de la estructura y el funcionamiento de la mega-iglesia nos permiten aproximarnos a la comprensión de la dinámica creciente y movilizadora que caracteriza a este tipo de organización religiosa neo-pentecostal. Al respecto es interesante 
analizar la relación entre dicho "estar" y el "estar en movimiento" en cuanto supone una superación de apreciaciones estáticas de lo social y lo impulsa hacia una visión dinámica que desde la "llegada al evangelio" lo lleva a transitar, a través de un cierto "pasaje" hacia una transformación paulatina de su vida cotidiana pero también respecto a una participación creciente en la vida de la Iglesia. Un estar en movimiento claramente visible en el "régimen de circulación e intercambio". Desde otro ángulo el abordaje del "sufrimiento" adquiere también una importancia notable en la cual las instancias del dolor y la enfermedad, de la fatalidad y la muerte, lejos de constituirse en instancias disociadas de la experiencia cotidiana son articuladas a través de la diversidad de ritos y prácticas que las abordan y resignifican. Si el sufrimiento constituye una instancia desestructuradora "del mundo de la vida de los sujetos" (p. 186) la práctica del evangelio conduce a un ejercicio constante de reestructuración sobre un sentido nuevo en la vida del creyente. Asi si "todo es por algo" no hay algo que no tenga que ver con ese todo. Una situación que lleva a un cambio notable en la valoración "de las experiencias negativas" que sufre el sujeto (p. 199), pero un cambio que se traducirá asimismo en un complejo proceso de "reconversión" y de "revalorización" que converge en una "calificación diferencial del creyente en un área específica de su vida" (p. 203). Un cierto proceso de resemantización con múltiples implicancias en su vida personal y social. La relevancia en dicho proceso se explicita también en una importante recuperación que puede hacerse de elementos de otros universos simbólicos, como es el caso del psicoanálisis y los discursos de autoayuda y que redundará directamente en la llamada teología de la sanidad. Un discurso sobre la salud que en el templo "Rey de Reyes" desplaza incluso, como lo señala el autor, otro tipo de manifestaciones sobre el cuerpo.

$\mathrm{Al}$ arribar a las conclusiones Algranti retoma varias de sus preguntas iniciales relacionadas con dicha relación entre al religión y la política especialmente en la necesidad de explorar la posible existencia de una dimensión política dentro de las Mega-iglesias evangélicas y en este caso en la Iglesia de Rey de Reyes en Bs. As.

Es allí en donde emergen las primeras afirmaciones vinculadas con una cierta emergencia de la política considerando la singularidad del caso argentino "no en términos exclusivamente partidarios" sino bajo una forma de asociación colectiva tendiente a "llevar" el evangelio "a los espacios de influencia de la Argentina". Instancias en donde sobresalen por un lado la relevancia 
de la "producción discursiva de la unidad del movimiento evangélico" como por otro lado la figura del "líder" como "sujeto del cambio social". Un sujeto llamado a tener un protagonismo fundamental en el cambio de la sociedad sea cual fuere el mismo.

El trabajo, como hemos podido señalar logra responder varios de los interrogantes planteados inicialmente, si bien otros quedan pendientes, especialmente aquellos referidos a la potencialidad de los líderes para responder a los problemas de la representación y la demanda en el movimiento evangélico o como señala el autor la pregunta respecto a si pueden estos líderes pasar de los reclamos vinculado con la reivindicación de derechos y libertades religiosas a reclamos relacionados con problemáticas políticas sociales o sea ¿pueden "reapropiarse" de exigencias políticas y espiritualizar de alguna manera los reclamos sociales?

Muchas preguntas que surgen de un texto bien escrito y que realiza una importante esfuerzo hermenéutico para acercarse respetuosamente al conocimiento de un fenómeno relevante en el campo religioso de nuestra sociedad. 
BIONDI, Karina. Junto e misturado: uma etnografia do PCC. São Paulo: Terceiro Nome, $2010.245 \mathrm{p}$.

\section{Messias Basques \\ Mestre em Antropologia Social - Brasil}

Se é menos fatigante descer que subir, o pensamento no entanto não pensa lealmente senão contra a corrente?

Pierre Clastres

Essa é uma etnografia herege. O leitor encontrará nas páginas desse livro uma interpretação etnográfica inteiramente diversa das teses canônicas estabelecidas por uma imaginação sociológica standard a respeito do que se convencionou chamar de "crime organizado". ${ }^{1}$ O livro de Karina Biondi é antes de tudo um convite a ver de modo diferente um coletivo composto por detentos do universo prisional paulista: o Primeiro Comando da Capital (PCC). O desafio seguido pela autora pode ser assim resumido: seríamos capazes de "levar a sério" o que pensam e dizem as pessoas que decidimos estudar (sobretudo) quando estão associadas a práticas criminosas?

Tal impasse lança luz sobre uma erva daninha que vez por outra arboresce no ofício de antropólogo: o apego demasiado que nutrimos (ainda que de modo inconfessado) pela ideia de "apercepção sociológica". ${ }^{2}$ Segundo esse axioma, caberia ao antropólogo explicar e conferir inteligibilidade àquilo que observa, posto que os "nativos" sejam inconscientes das "leis" que regem o funcionamento dos processos que eles próprios protagonizam. Exemplos disso podem ser facilmente encontrados na literatura antropológica e nas ditas ciências sociais: "Tomar por realidade as crenças e os discursos das pessoas (mesmo as ricas e cultivadas), significa converter em princípio de explicação

1 Para uma amostra desse tipo de abordagem nas ciências sociais, ver Dossiê crime organizado (2007).

2 Ver Louis Dumont (1992, p. 55). 
o que está pedindo para ser explicado.” (Durand, 2003 apud Bourdieu; Darbel, 2003, p. i).

Se é verdade que "a antropologia procura elaborar a ciência social do observado" (Lévi-Strauss, 1954, p. 379, tradução minha), então se deve instituir um "dispositivo antinarciso" capaz de fazer com que a disciplina não se contente "em descrever o ponto de vista nativo para, ato contínuo, apontar seus pontos cegos - englobando 'criticamente' o ponto de vista do nativo dentro do ponto de vista do observador" (Viveiros de Castro, 2009, p. 15). Karina Biondi promove uma fecunda "corrupção idiomática"3 ao apresentar o funcionamento do PCC no ambiente carcerário por não pressupor que as falas de seus interlocutores sejam mentiras, crenças, falsetas. A sua experiência etnográfica nos dá a conhecer as teorias políticas dos prisioneiros que compõem esse coletivo e permite que o discurso desses personagens possa ser visto como "discurso sábio". ${ }^{4} \mathrm{E}$ o leitor verá, desde o início, que qualquer acusação de "apologia" só tem lugar se, e apenas se, lermos esse livro sob o viés moralista que nos faz associar certas condutas às noções de "má índole" e de "naturezas" vis. Essa é uma experiência de conhecimento, onde não cabe ao antropólogo fazer as vezes de inquisidor ou juiz.

Fruto de uma pesquisa de quase seis anos, Junto e misturado: uma etnografia do PCC foi originalmente escrito como dissertação de mestrado. A introdução relata os problemas de uma inserção "involuntária"5 no ambiente carcerário cujas idas a campo eram, por conseguinte, indissociáveis dos dias de visita. ${ }^{6}$ Segundo a autora, foi a maneira assistemática de trabalho que a

\footnotetext{
3 Ver Goldman (2006, p. 169-170).

4 Faço remissão à análise de João Adolfo Hansen sobre Grande sertão: veredas. Para Hansen (2000, p. 20), seria possível pensar João Guimarães "Rosa como escritor que produz dispositivos de heteróclito, o grande e o estranho feito de seus textos consiste em reescrever a própria língua". "[Riobaldo é uma] espécie de Macunaíma a sério, por sua boca passa o mito como vontade de fundar uma origem a partir da qual representações imaginárias, formações ideológicas se intertextualizam e, fazendo-se como fala, dão-se como história na estória." (Hansen, 2000, p. 34, grifo meu). E prossegue o autor: "Quando produz certa percepção selvagem - principalmente em personagens de sua eleição, como crianças, loucos, bêbados, desqualificados - ele [João Guimarães Rosa] o faz desconstruindo o imaginário acumulado sobre o sertão, evidenciando que este não é natureza como tanta vez a ficção romântica ou naturalista quis fazer crer, mas meramente um diverso cultural dotado de historicidade própria, cujos códigos passam por fora da cultura ilustrada, ainda que sejam determináveis a partir dela, no que se revela antropólogo em tempos etnocêntricos." (Hansen, 2000, p. 35).

5 O marido de Karina Biondi foi preso no ano de 2003.

6 Palavras grafadas em itálico referem-se a termos nativos, com exceção das expressões em idioma estrangeiro.
}

Horizontes Antropológicos, Porto Alegre, ano 17, n. 35, p. 410-418, jan./jun. 2011 
permitiu vislumbrar a existência também assistemática de seu objeto de pesquisa. A "autorização" que obteve por parte de alguns prisioneiros não foi repassada até o topo de uma escada de posições hierárquicas em cujo cume estariam os líderes encarcerados do "crime organizado". Bastou o diálogo com alguns presos e o envio de uma publicação para que eles próprios pudessem tomar ciência do que a autora pretendia ao abordá-los. O aval de alguns irmãos se deu pela mesma via com que eles debatem e promovem consensos, uma vez que todos e cada um de seus membros falam em nome do Comando. Em contrapartida, a pesquisadora deveria respeitar as regras de "etiqueta" esperadas de toda e qualquer pessoa cuja condição é a de visita.

Daí que o método empregado para a pesquisa tenha sido também produtivamente corrompido por imperativos colocados pelos acasos, acontecimentos, enunciados, mudanças e imponderáveis que permeiam o cotidiano prisional. "Seguir os atores" implicou o convívio nas filas de espera, o constrangimento das revistas íntimas, a presença nos pátios em que familiares e prisioneiros se encontram, bem como a constituição de relações para além dos muros das instituições prisionais, dissolvendo a imagem segundo a qual ao fim do expediente o etnógrafo deixa o campo e retorna à sua rotina.

O primeiro capítulo apresenta uma breve história do PCC na qual se podem conhecer as diferentes versões para o seu nascimento, seja pelo prisma de seus membros, seja pelo que diz o discurso jurídico-policial. O "massacre do Carandiru", em 1992, o crescimento vertiginoso da população carcerária nessa década e a "megarrebelião" de 2001 são fatores indissociáveis da paulatina consolidação do coletivo no ambiente carcerário paulista. O fato curioso é que a versão que "vingou" entre os seus membros proceda do livro Cobras e lagartos, do jornalista Josmar Jozino (2004), que teve grande "repercussão no universo prisional, [e] ajudou na divulgação do mito de origem publicado" (p. 70). A criação do PCC é vista por muitos presos como o fim de um tempo no qual imperava uma guerra de todos contra todos, onde a ordem era "cada um por si" e "o mais forte vence". (p. 71).

Como reação à visibilidade que o coletivo aos poucos angariou, o poder público tentou a todo custo promover a sua contenção. Seu nome foi suprimido de noticiários e veículos de imprensa e fez com que secretários de segurança pública tergiversassem quando perguntados a seu respeito. O PCC, por sua vez, rompeu o silêncio com uma "megarrebelião" em maio de 2006, na qual foram envolvidas 84 instituições penitenciárias e que resultou num total de 
299 ataques a órgãos públicos, 82 ônibus incendiados, 17 agências bancárias alvejadas a bombas, 42 policiais e agentes de segurança mortos e 38 feridos. Se ainda havia dúvidas em relação à presença do PCC fora das prisões, a amplitude dessas ações a colocou em evidência. $\mathrm{O}$ que se pensava só existir nas prisões ou nos bairros periféricos ganhou visibilidade, por meio da violência, nas regiões centrais das cidades (p. 75-76).

Atônitos, intelectuais e pesquisadores da temática criminal foram conclamados a desvendar as razões dos atentados. Formou-se à época um senso comum sobre a estrutura organizacional do PCC, enquanto o seu sucesso fora tributado à falta de controle e de rigor na coibição de suas práticas por parte do poder público. ${ }^{7}$ Pouco se falou das demandas dos prisioneiros, do descumprimento da Lei de Execuções Penais pelo próprio Estado mediante procedimentos inconstitucionais como o Regime Disciplinar Diferenciado, da prática regular de maus tratos e tortura denunciados por movimentos em defesa dos Direitos Humanos.

Karina Biondi confronta as teses tecidas à época com uma minuciosa descrição etnográfica do modo de funcionamento do PCC. Daí em diante, seu texto permitirá ao leitor acompanhar o percurso que transforma um preso em irmão e membro do Partido. Os Centros de Detenção Provisória (CDPs) são a faculdade dos recém-detidos, o espaço-tempo nos quais se dá a aprendizagem das teorias do universo prisional, a construção de suas reputações e a passagem de primários a residentes (p. 85, 88). Seria dessa maneira que os detentos aprenderiam o que chamam de proceder, conceito que condensa as injunções e prescrições que orientam toda a existência do preso. Ao inverso do que professa o discurso jurídico-policial, "o poder [do PCC] não se exerce de forma descendente e tampouco é localizável, [pois] não é a relação com a instituição que está em jogo, mas antes de tudo a relação entre presos". Logo, o proceder "é o nome de uma relação travada por prisioneiros entre si, com funcionários e visitantes, e que dispõe sobre o comportamento esperado em cada situação de suas vidas". (p. 95)

O prisioneiro convidado a participar do Comando deve ter proceder. Quem não se "garante" pode sofrer a consequência de ser excluido, deixar de

\footnotetext{
7 Ver Dossiê crime organizado (2007).
} 
ser irmão e de correr com o Partido, sendo destinado ao seguro, um local reservado aos presos que não respeitam os ideais do PCC. ${ }^{8}$ Esse "conhecimento do proceder e do funcionamento da vida prisional é um dos elementos avaliados antes do convite para o batismo, momento no qual o primo se torna irmão" (p. 98). Além disso, "como ser batizado implica assumir um compromisso com o Crime, muitos presos só optam pelo batismo quando são condenados a uma longa permanência na prisão e são transferidos para Penitenciárias. Esta é uma decisão sem volta." (p. 98).

Em suas visitas a diversos presídios, Karina Biondi pôde observar que essa "ética" revela também uma "estética da socialidade" dos presos entre si e perante seus familiares e funcionários do sistema prisional. O irmão deve, sobretudo, ser humilde e respeitar o ideal de igualdade, que é uma característica, uma habilidade, ascese, postura e atitude que todo irmão deve ter. Sua "cabulosidade" está em não se deixar oprimir, está em manter sua posição de igual. Nessa complexa trama cotidiana que constitui noções de pessoa a todo tempo cambiáveis, "se o ideal de Igualdade busca apagar as diferenças entre os presos, tornando-os todos primos, o tornar-se irmão só é possível a partir de uma diferenciação" (p. 101) "uma diferença de capacidade e de habilidade política que costuma ser adquirida ao longo de sua estadia na cadeia" (p. 102).

O segundo capítulo parte das transformações por que o PCC passou desde o seu nascimento para apresentar sua composição nos dias que correm. Debate-se assim a dissolução que Marcos Willians Herbas Camacho ("Marcola") teria promovido na estrutura hierárquica em que o Comando fora originariamente concebido. Tido pelo poder público como líder do PCC, espécie de "anti-herói cultural" da cosmogonia do "crime organizado", Marcola é reconhecido pelos prisioneiros como o responsável pelo sucesso do movimento de dissolução da hierarquia no PCC, o qual fora reforçado pela incorporação da igualdade ao lema Paz, Justiça e Liberdade (p. 107). No entanto, se esse princípio conjura a hierarquia nas relações entre presos nas cadeias do $P C C$, também faz irromper conflitos que perpassam o limiar do poder de uns sobre os outros no exercício de "posições políticas específicas que exacerbam

\footnotetext{
8 Para uma análise do "proceder” e da divisão espacial “convívio”-“seguro”, ver Marques (2009).

9 Tomo de empréstimo a intuição etnográfica de Joanna Overing (1991), não obstante o conceito tenha sido originalmente aplicado ao contexto indígena amazônico.
} 
e colocam em evidência as habilidades dos irmãos: piloto, faxina, torre" (p. 109). Afinal, as decisões que cada qual precisa tomar não podem refletir interesses individuais, sendo antes entendidas como manifestações dos ideais do coletivo: guerra com os polícias e paz entre os ladrões.

A prisão, nesse sentido, constituiria uma arena política onde são travadas disputas por objetivos que são públicos e na qual a produção do PCC está intimamente ligada à seguinte pergunta: qual é o papel desempenhado pelos irmãos quando assumem as negociações entre os presos e os funcionários, atores que possuem interesses diversos, intervindo em situações de conflito, buscando algum acordo? (p. 125) De fato, diz a autora, "os termos 'líder' e 'liderança' não são encontrados na gramática utilizada pelos prisioneiros e, pelo que a pesquisa de campo me revelou, não se trata de um recurso para driblar as acusações do poder público" (p. 127).

O que estaria na base da tensão entre a igualdade e o exercício político no PCC é a inexistência de obrigações, porque almejam fundar "um Comando entre iguais, ou melhor, um Comando sem comando" (p. 141). As reflexões dos prisioneiros "[impediriam] a criação de um postulado sobre a vida prisional e, consequentemente, a consolidação de uma teoria" (p. 148, grifo da autora), enquanto os crimes praticados pelos seus membros constituem atividades individuais (os seus corres) que não se confundem nem são a condição de existência do PCC. Vê-se, portanto, que "a atuação de um membro junto aos outros presos e à administração da instituição prisional extrapola a questão criminal para adotar uma função política que é fruto de reflexões teóricas ininterruptas" (p. 155).

O terceiro capítulo propõe uma crítica das categorias "crime organizado" e "organização criminosa" a partir do ideal de igualdade. Se tais categorias correspondem à forma encontrada pelo poder público para tornar possível a criação de uma "pessoa jurídica" cuja punição seja coextensiva àqueles que dela fazem parte, não caberia ao antropólogo apreender o conceito do "outro", ou seja, daqueles entre os quais decidiu estudar? Se o objetivo é "levar a sério" o que dizem os "nativos", como definir o PCC senão de modo etnográfico? Eis os desafios.

A dificuldade em escapar ao idioma juridicista revela um vício nocional que insiste em constranger a imaginação conceitual, fazendo-a aderir a uma 
teologia responsável pelo vaticínio: "onde estiverem dois ou três reunidos" se encontrará uma entidade transcendente, onipresente e onisciente; aí estará o crime organizado "no meio deles". ${ }^{10} \mathrm{O}$ crime organizado, a sociedade, a lógica do englobamento do contrário são reflexos de um "pensamento geometral", que almeja sintetizar todas as perspectivas parciais num "julgamento de Deus" que superaria e deteria todos os juízos particulares (ver Veyne, 1978, p. 23). Em contraponto, é digna de nota a narrativa da impressionante "desorganização" coletiva que culminou na viagem de milhares de parentes de presos rumo à Brasília, onde se manifestaram contra os maus-tratos no regime prisional. É de se esperar que o leitor se faça a mesma pergunta que a autora fez a um dos participantes: "[...] 'Com tudo o que aconteceu, achei que só chegariam lá meia dúzia de pessoas, mas chegaram 2 mil. Como pode? [...] Não tem segredo. Pensa: cada uma daquelas pessoas queria estar lá, ué!’.” (p. 181).

No quarto capítulo, Karina Biondi trata da "força que garante que uma formação aparentemente tão frágil, em função de sua instabilidade, perdure. Trata-se do PCC como força exterior, capaz de produzir disposições e associações" (p. 191). Sua antropologia imanentista, isto é, atrelada ao que era dito e vivido por seus interlocutores, abre espaço para uma definição alternativa ao abordar o PCC, elaborando "uma torção do conceito de transcendência" (p. 194). Embora essa força transcendente percorra a imanência do funcionamento do coletivo, ela não evoca a ideia clássica de "representações coletivas". A conceituação etnográfica da transcendência, como se poderá ver, não é de mesma natureza que a doutrina teológica segundo a qual Deus é, nas palavras de Leibniz, "aquilo que um inventor é para a sua máquina, aquilo que um príncipe é para os seus súditos” (Lalande, 1999 apud Biondi, 2010, p. 195).

Trata-se de uma força que não se confunde com os participantes do PCC, mas que é responsável pelas suas associações, movimentos e disposições, ao mesmo tempo em que é por eles produzida. Segundo Biondi, os participantes do PCC lançam mão de "processos de desindividualização" que seriam responsáveis pela repressão de qualquer manifestação individual dos irmãos

${ }^{10}$ Faço alusão ao livro de São Mateus, capítulo 18, versículo 20 da Bíblia e ao artigo segundo da Convenção de Palermo (ONU, 2002) que define "grupo criminoso organizado" como: "Grupo estruturado de três ou mais pessoas, existente há algum tempo e atuando concertadamente com o propósito de cometer uma ou mais infrações graves ou enunciadas na presente convenção, com a intenção de obter, direta ou indiretamente, um benefício econômico ou outro benefício material.” (p. 158).

Horizontes Antropológicos, Porto Alegre, ano 17, n. 35, p. 410-418, jan./jun. 2011 
(estejam eles atuando como faxinas, pilotos ou torres). O fato de os irmãos ou as torres não serem, no exercício de suas funções, considerados atores individuais conjura a existência de hierarquia entre os participantes do PCC (p. 203). A diferença não hierárquica surge, aqui, como uma face do processo de individuação que tem início com a "graduação" nas faculdades, como uma distribuição diferencial da posição de "sujeito," ou a presença de uma funçãoEu de caráter eminentemente político. ${ }^{11}$

Se não há indivíduo, tampouco há algo que se possa chamar grupo. "O que existe é uma mistura. Se a igualdade conduz à mistura, aqueles que não são de igual deixam de ser a população, de estar misturados, para serem individualizados.” (p. 206), ou seja, para deixarem de ser irmãos. Eis a questão central do livro, pois "o PCC aparece como uma existência autônoma aos seus membros, mesmo que sua existência seja sustentada pela atuação dos irmãos. Cada um deles se considera responsável pelo Comando e afirma ser sua a obrigação de dar o exemplo, pois o PCC, ali, são eles." Como dizem, "o Comando está acima de tudo; tamo junto e misturado" (p. 207-208, 218).

Ao cabo desse périplo, se poderá ver que Karina Biondi rompe a linha de estudos sobre criminalidade feitos ao parapeito da "varanda" e em gabinetes com ar refrigerado nos quais os analistas se informam através das estatísticas do Estado e pelo noticiário policialesco, livres do contato direto com os sujeitos que são objetos de suas pesquisas. Ao fazê-lo, a autora revela o complexo modo de funcionamento e as teorias políticas de um coletivo aquém e além da semelhança pressuposta em face do par indivíduo/sociedade. Este é um escrito que coloca em xeque a atitude aparentemente benevolente que enuncia o direito do "nativo" a elaborar as suas próprias reflexões quando, em verdade, cabe ao próprio antropólogo suspender o juízo de valor (epistemológico) que faz do conhecimento uma prerrogativa de quem observa. $\mathrm{O}$ "nativo" não precisa ser licenciado a refletir - "posso, logo penso" -, pois somos nós que devemos fazer da etnografia uma experiência de aprendizagem com outrem. Por intermédio de seus interlocutores, este livro nos dá um acesso privilegiado ao universo do Primeiro Comando da Capital.

11 Para uma crítica etnográfica ao conceito de "grupo" à luz da socialidade do povo indígena yudjá, ver Lima (2005, p. 90). 


\section{Referências}

BOURDIEU, P.; DARBEL, A. O amor pela arte: os museus de arte na Europa e seu público. São Paulo: Editora da USP: Zouk, 2003.

DUMONT, L. Homo hierarquicus: o sistema de castas e suas implicações. São Paulo: Edusp, 1992.

GOLDMAN, M. Alteridade e experiência: antropologia e teoria etnográfica. Etnográfica, v. 10, n. 1, p. 161-173, 2006.

HANSEN, J. A. $O$ o: a ficção da literatura em Grande Sertão: Veredas. São Paulo: Hedra, 2000.

DOSSIÊ CRIME organizado. Revista de Estudos Avançados, v. 21, n. 61, set./ dez., 2007.

JOZINO, J. Cobras e lagartos. São Paulo: Objetiva, 2004.

LÉVI-STRAUSS, C. Place de l'anthropologie dans les sciences sociales et problèmes posés par son enseignement. In: LÉVI-STRAUSS, C. Anthropologie structurale. Paris: Plon 1954. p. 377-418.

LIMA, T. S. Assimetria $=f(\mathrm{Eu})$. In: LIMA, T. S. Um peixe olhou pra mim: o povo Yudjá e a perspectiva. São Paulo: NuTI: Unesp: ISA, 2005. p. 75-129.

MARQUES, A. Crime, proceder, convívio-seguro: um experimento antropológico a partir de relações entre ladrões. Dissertação (Mestrado em Antropologia Social)-Faculdade de Filosofia, Letras e Ciências Humanas, Universidade de São Paulo, São Paulo, 2009.

OVERING, J. A estética da produção: o senso de comunidade entre os Cubeo e os Piaroa. Revista de Antropologia, n. 34, p. 7-33, 1991.

VEYNE, P. M. Comment on écrit l'histoire. Paris: Seuil, 1978.

VIVEIROS DE CASTRO, E. Xamanismo transversal: Lévi-Strauss e a cosmopolítica amazônica. 2009. Mimeografado. 
FLEISCHER, Soraya; SCHUCH, Patrice (Org.). Ética e regulamentação na pesquisa antropológica. Brasilia: Letras Livres: Editora da Universidade de Brasilia, 2010. $248 \mathrm{p}$.

\section{Graziele Ramos Schweig*}

\section{Universidade Federal do Rio Grande do Sul-Brasil}

Em consonância com o cenário contemporâneo de desafios lançados à antropologia, o livro Ética e regulamentação na pesquisa antropológica ${ }^{1}$ vem contribuir para a reflexão acerca das atuais condições de produção do conhecimento antropológico frente a dois elementos: as instâncias externas de regulação ética em pesquisa e a realização de pesquisa antropológica desde contextos não acadêmicos. Em ambos os casos, está em jogo o modo como a antropologia é desafiada a dialogar com outros profissionais e áreas de conhecimento, repensando, nesse processo, sua própria tarefa enquanto disciplina.

Lançado em junho de 2010, o livro é produto de um evento homônimo, também organizado por Soraya Fleischer e Patrice Schuch, que ocorreu na Universidade de Brasília, em novembro de 2009. A proposta do evento era discutir as formas de regulamentação da pesquisa antropológica especialmente em espaços não tradicionalmente familiarizados com a disciplina. Desses espaços, enfatizam-se os comitês de ética em pesquisa abrangidos pelo Sistema Conep (Comissão Nacional de Ética em Pesquisa) e regulados pelas Resoluções 196 e 304 de 1996, do Conselho Nacional de Saúde (CNS). De modo não tão central, o livro também traz reflexões sobre a inserção da pesquisa antropológica em espaços não acadêmicos, como no trabalho de perícia e de consultoria.

Assim como o seminário que the deu origem, o livro é organizado em três partes, sendo cada uma delas composta por artigos dos participantes do evento e acompanhada de um comentário crítico por parte das organizadoras e

* Doutoranda em Antropologia Social.

1 O livro está disponível no endereço: http://www.anis.org.br/arquivos_etica_antropologica.pdf. 
por Ximena Pamela Bermúdez. Faz-se notar a diversidade de perfis dos autores que participam do livro, envolvendo tanto pesquisadores consagrados no campo da pesquisa antropológica quanto pesquisadores em início de carreira; antropólogos inseridos em espaços não acadêmicos e representantes de outras áreas de conhecimento. Tanto pela forma de organização do livro como pela diversidade de falas, as organizadoras deixam clara a intenção de ampliar o debate sobre ética e regulamentação para além das fronteiras disciplinares. De forma panorâmica, descrevo a seguir a composição do livro, seus autores e temáticas, antes de adentrar em algumas questões transversais que se fazem presentes.

A primeira parte do livro problematiza questões relacionadas à ética em pesquisa desde a perspectiva da tradição antropológica. Para tanto, reúne artigos de três experientes pesquisadores: Luis Roberto Cardoso de Oliveira, Claudia Fonseca e Ciméa Barbato Bevilaqua. Na segunda parte do livro são reunidos artigos que problematizam experiências vivenciadas durante a realização de pesquisas antropológicas e sociológicas frente à regulamentação ética. Três artigos, de Dora Porto, Fernanda Bittencourt Vieira e Raquel Lima, discutem questões enfrentadas na pesquisa acadêmica (mestrado e doutorado) em instituições e serviços de saúde no que tange à relação com comitês a partir do Sistema Conep. Já o artigo de Luciane Ouriques Ferreira apresenta reflexões sobre ética que emergiram durante a elaboração de estudo de saúde indígena, encomendado pela Fundação Nacional de Saúde (Funasa). Na terceira e última parte, intitulada "A perspectiva dos órgãos regulamentadores", são apresentadas, no artigo de Débora Diniz e no de Dirce Guilhem e Maria Rita Novaes, experiências que buscam um diálogo entre ética biomédica e pesquisas sociais. Já a discussão apresentada no artigo de Elaine Amorim, Kênia Alves e Marco Paulo Fróes Schettino centra-se nas especificidades do trabalho pericial em antropologia.

De modo geral, os autores são unânimes quanto às limitações da regulamentação ética do Sistema Conep, apontando o modo como seus parâmetros nasceram de preocupações com os abusos da ciência médica e, desde essa área específica, são hegemonicamente impostos às demais ciências cujas pesquisas envolvem seres humanos. Assim, vários artigos apontam as dificuldades da pesquisa antropológica frente ao Sistema Conep, especialmente a partir de situações concretas envolvendo comitês de ética, narradas na segunda parte do livro - entendimentos estritos da assinatura do Termo de Consentimento Livre 
e Esclarecido (TCLE) e pareceres versando mais sobre a metodologia do que sobre a ética dos projetos de pesquisas sociais são exemplos da dificuldade de entendimento da área biomédica para com a antropologia. Contudo, se a constatação dos limites desse sistema é consenso, diferentes caminhos são propostos para a resolução dos impasses da pesquisa social frente a ele, sendo que tais caminhos evidenciam concepções distintas de ética e de ciência.

Percebe-se que ao identificarem esse impasse, alguns autores tendem a enfatizar a criação de critérios específicos de julgamento ético para as pesquisas sociais, reiterando a distinção feita por Luis Roberto Cardoso de Oliveira entre pesquisas com e $\mathrm{em}$ seres humanos - e, associado a isso, tendendo a reforçar a divisão entre ciências humanas e naturais. Outros autores apontam a necessidade de construção conjunta de regras unificadas, englobando distintas ciências em um debate comum sobre ética. Com relação a isso, Débora Diniz comenta acerca da existência de sistemas alternativos de ética em pesquisa e apresenta a experiência do Comitê de Ética em Pesquisa do Instituto de Ciências Humanas da UnB, que inicialmente se configurou como um comitê independente, especializado em pesquisas sociais e, após dois anos de funcionamento, vinculou-se ao Sistema Conep. O que essas duas tendências possuem em comum é uma concepção de ética definida como um conjunto de regras e princípios elaborado por especialistas, seja a partir de um recorte disciplinar, construindo parâmetros específicos para determinadas áreas de conhecimento, seja esforçando-se por dialogar interdisciplinarmente.

Diferentemente disso, o artigo de Claudia Fonseca trabalha com uma concepção de ética como um fórum de deliberação democrática, aberto também à participação de leigos. A esse conceito de ética subjaz uma visão da ciência como processo, sujeito permanentemente a novos embates éticos diante das dinâmicas sociais, não podendo ficar restrito a regras fechadas elaboradas por especialistas. Fundamentalmente, Fonseca aponta a indissociabilidade entre técnica, ética e política na ciência, seja ela humana ou natural. Em outras palavras, todas as pesquisas são feitas com seres humanos, não podendo ser a questão ética resolvida de forma simples para qualquer ciência. Além disso, Ximena Bermúdez lembra que nos próprios princípios do Sistema Único de Saúde está a integralidade, a qual pressupõe a diversidade de saberes acerca da saúde. De fato, parece um contrassenso que o próprio Conselho Nacional de Saúde aprove normas éticas tão centradas na lógica biomédica quando as políticas de saúde preconizam o trabalho multiprofissional e o cuidado integral. 
Em seu artigo, Luis Roberto Cardoso de Oliveira aponta que esse tipo de regulamentação externa, como o Sistema Conep, atinge muito mais a pesquisa realizada em universidades e institutos de pesquisa, raramente influindo sobre a pesquisa antropológica feita em ONGs e órgãos públicos. Sobre isso se faz pertinente o debate trazido por Elaine Amorim, Kênia Alves e Marco Schettino, os quais argumentam que, mesmo tendo a etnografia como fundamento, o trabalho pericial em antropologia se diferencia da pesquisa acadêmica, tanto em relação às condições de produção como em relação ao tipo de questionamento que orienta a pesquisa. Nesse sentido, os autores discutem as particularidades do trabalho pericial, buscando formular princípios éticos que deem conta das questões que o cercam.

Enfim, o livro Ética e regulamentação na pesquisa antropológica explora os desafios que a antropologia enfrenta ao se confrontar com outras áreas de conhecimento, mais ou menos hegemônicas, apontando a necessidade de uma discussão não apenas de fundo ético, mas epistemológico e político quanto ao ofício do antropólogo. Além disso, a discussão apresentada demonstra a necessidade de inserir no debate acadêmico reflexões sobre as implicações éticas (também epistemológicas e políticas) das pesquisas realizadas fora do âmbito acadêmico, abrindo os olhos para uma crescente realidade: a produção de pesquisa antropológica a partir de outros espaços, com condições e exigências específicas em torno desse saber. 
STRYKER, Rachael. The road to Evergreen: adoption, attachment therapy, and the promise of family. Ithaca: Cornell University Press, 2010. $192 \mathrm{p}$.

\section{Sonja van Wichelen \\ University of Western Sydney - Austrália}

Foram publicados muitos livros sobre o tema da adoção durante a última década. Muitas vezes focados no processo adotivo, se referem a questões de identidade, raça e a produção de parentesco. O livro de Rachael Stryker, The road to Evergreen, entretanto, é uma exceção bem-vinda a essa lista. Ao invés de enfocar o processo adotivo per se, a autora dirigiu sua pesquisa antropológica para o assim chamado processo de pós-colocação. De forma original, ela examina - através da etnografia de uma clínica no Colorado (EUA) - o funcionamento de uma terapia controvertida de apego para famílias com crianças adotadas. Por que os pais escolhem terapias altamente contestadas? Quem são os sujeitos envolvidos? Como funciona a terapia? Quais as implicações da terapia para a noção de família?

Stryker enfoca o "modelo Evergreen" da terapia do apego. Inaugurada nos anos 1970 pelo psiquiatra Foster Cline, a terapia inclui técnicas confrontacionais, encorajando a criança a compartilhar seus sentimentos verbalmente ao segurá-la num abraço apertado e obrigá-la a olhar nos olhos do cuidador (a criança pode ser atada se houver risco de se tornar violenta). A psiquiatra Martha Welch refinou esse método para a redução de raiva e desenvolveu sua "terapia do aperto" (holding therapy), também conhecida como a Terapia da Compressão, O Vínculo Direto Sincrônico, e o Abraço Prolongado entre Pais e Filhos. ${ }^{1}$

A participação dos pais é central à terapia de Welch: não são os terapeutas e, sim, os pais que realizam a sessão do aperto enquanto os terapeutas supervisionam o processo. As sessões de terapia na clínica fazem parte, em

1 Em inglês: Compression Therapy, Direct Synchronous Bonding (DSB) e Prolonged Parent Child Embrace (PPCE) (N. de T.). 
geral, da estadia no lar terapêutico onde a criança recebe cuidados terapêuticos constantes e onde os pais observam novas técnicas parentais. Aqui, as crianças aprendem a moderar seu comportamento de forma que possam "elaborar seus pensamentos, fazer escolhas apropriadas, aceitar responsabilidade por suas ações, e desenvolver uma 'voz interna'(consciência)" (p. 23).

O modelo Evergreen de terapia do apego é controvertido por causa de diversos casos muito comentados pela mídia em que crianças foram mortas durante ou logo depois de seu tratamento (conforme o método) por uma síndrome conhecida como "desordem reativa de apego", ou reactive attachment disorder (RAD). Muitos pesquisadores criticam o tratamento por ser um tipo de pseudociência ou, pior, abuso infantil. Não é, entretanto, a intenção de Stryker debater se o modelo Evergreen é "bom" ou "ruim". Ao invés, tal como explica no primeiro capítulo, seu objetivo é examinar - através da análise etnográfica do modelo Evergreen - os "termos e os envolvimentos profundamente codificados que são associados com a reprodução social do amor pelas crianças na América” (p. 25). Ela visa demonstrar até onde irão os pais para "fazer e preservar a família americana" (p. 25). Dessa maneira, nos leva para uma compreensão mais sutil da institucionalização da noção de família.

Nos próximos cinco capítulos, a autora descreve seu trabalho empírico com as variadas etapas do processo: a maneira como as pessoas formam suas ideias sobre família e decidem adotar uma criança (cap. 2); a maneira em que as agências de adoção constroem normas para "famílias felizes" (cap. 3); as realidades pós-colocação (cap. 4); a terapia de confrontação na clínica (cap. 5); e o funcionamento do lar terapêutico (cap. 6). Enquanto os primeiros dois capítulos consideram o modo com que os pais e as agências de adoção constroem noções idealizadas de família e amor pelas crianças, os capítulos subsequentes incluem histórias comoventes de como crianças - por causa de suas histórias de abuso (sexual, entre outros) e dos efeitos da institucionalização prolongada - funcionam mal nas suas novas famílias. Transgridem normas higiênicas, urinando ou defecando em qualquer lugar da casa; têm comportamentos sexuais inadequados com seus irmãos; algumas delas se tornam violentas, ameaçando as pessoas circundantes. Para muitos pais que já esgotaram todos seus recursos para ajudar seus filhos (incluindo as várias formas de terapia da fala e da brincadeira), a terapia Evergreen de apego chega como uma última aposta. Muitas vezes, ficam eufóricas quando descobrem (por outras pessoas ou pela internet) as teorias sobre RAD. Tal como Stryker 
diz, "o diagnostico de RAD fornece uma oportunidade atraente para que [os pais] reformulem o comportamento negativo de seus filhos, o definindo em termos de patologia e, assim, legitimando suas próprias práticas parentais e expectações iniciais quanto à família, e ao mesmo tempo localiza a origem do problema dentro da criança" (p. 100). Não é portanto surpreendente que os pais abracem o discurso médico. É muitas vezes sua única chance para preservar ou fixar sua ideia de família.

Os capítulos 5 e 6 descrevem em detalhe os vários componentes da terapia Evergreen. Stryker evoca o processo inteiro ao focalizar uma família, os Korhonens, um casal - Betty e Marvin - que foi procurar tratamento para seu filho, Luke, com 15 anos de idade. O programa Evergreen consiste de um estágio intensivo de duas semanas durante as quais as famílias são submetidas ao regime da clínica. O relato de eventos é por vezes violento. Além de implementar regras rígidas e técnicas disciplinares de castigo para maus comportamentos, as primeiras sessões eram desenhadas para desequilibrar Luke e para avaliar suas emoções "genuínas" pela aplicação da "terapia do aperto". Sentado no colo do terapeuta e obrigado a manter contato ocular, Luke é chamado a responder perguntas muito pessoais rapidamente e sem hesitação. Luke não tem ideia de quanto tempo estará nessa situação, nem se dá conta de que seus pais o observam através de uma janela espelhada. Em sessões subsequentes, os terapeutas e pais confrontam as emoções de Luke através de role playing. Imitando o passado, eles supõem levá-lo a reviver seus traumas infantis, na esperança que ele rejeite sua mãe de nascimento e abrace seus pais adotivos. Todos, mas especialmente Luke, estão emocionalmente esgotados depois das sessões. A alternância entre sentimentos de raiva, medo, ansiedade e tristeza é suposta criar vínculos poderosos entre os membros da família. Nas semanas seguintes, a família continua a terapia na clínica e na casa terapêutica. Betty e Marvin também fazem uma terapia de casal. No final das duas semanas intensivas, conforme as consequências da terapia do aperto e todas as observações na casa, os terapeutas do apego estabelecem um plano para o tratamento a longo prazo e a família está pronta para ir para casa. Se bem que não seja exatamente da maneira como os Korhonens imaginavam, vão continuar uma família.

O caso dos Korhonens é considerado um sucesso. É o caso de apenas a metade das famílias que procuram tratamento. No caso das menos exitosas, as crianças são reinstitucionalizadas para um tratamento a longo prazo 
na clínica, ou são colocadas em escolas militares, internatos ou residências coletivas. Porém, os terapeutas sugerem que mesmo essas circunstâncias não excluem a ideia de uma "família para sempre". Crianças exiladas serão "amadas a distância" (p. 160). Conforme Stryker, essa reformulação do fracasso da terapia "fornece uma oportunidade ímpar para os pais da clínica transformarem a família de um coletivo físico em um coletivo metafórico sem detrimento à categoria social" (p. 160). Mas tal perspectiva situa a criança como responsável tanto do sucesso com do fracasso da terapia. Neste último caso, "tornar a criança responsável pelo fracasso da terapia serve para ressignificar o resultado da terapia, tornando uma experiência ambígua em algo produtivo" (p. 160). O capítulo final reflete sobre a reprodução social do apego e sugere considerações acadêmicas para pesquisa futura.

The road to Evergreen é um livro fascinante, escrito numa prosa acessível - que evita o jargão típico de boa parte da produção acadêmica. Presta-se a uma leitura por acadêmicos e profissionais do campo de adoção, assim como por membros da tríade adotiva - pais adotivos, pais de nascimento e adotados. A escrita lúcida de Stryker não dispensa o vigor analítico. Empiricamente e analiticamente ela realiza seu objetivo - a demonstração de como a terapia do apego resgata a ideia de família. Apesar de sentir certa frustração pela falta de uma crítica contundente à terapia, admirei o esforço da autora para manter a proximidade etnográfica, indispensável para uma compreensão nuançada da popularidade desse tratamento. Fiquei também curiosa em aprender mais sobre os sujeitos desse livro - as crianças - como viveram a experiência e como atribuíram significado às terapias às quais foram submetidas. Mas esse é um outro assunto que mereceria ainda outro volume dessa pesquisa.

Traduzido do inglês por Claudia Fonseca. 